\title{
Plasma 17-hydroxyprogesterone concentrations in ill newborn infants
}

\author{
J F MURPHY, B G JOYCE, J DYAS, AND I A HUGHES \\ Department of Child Health and Tenovus Institute, Welsh National School of Medicine, Cardiff
}

SUMMARY Plasma 17-hydroxyprogesterone concentrations were determined in 47 preterm and term infants who were ill from a variety of causes. The results were compared with those in 53 healthy term infants. Mean plasma 17-hydroxyprogesterone values were appreciably higher in ill term and healthy preterm infants compared with healthy term infants, but the highest values were found in ill preterm infants. None of the infants had adrenal disease but some very ill infants had plasma 17-hydroxyprogesterone values approaching those seen in untreated infants with congenital adrenal hyperplasia. Interpretation of the results of plasma steroid measurements in newborn infants must take account of gestational age and the presence of stress related illness.

Since more than $90 \%$ of cases of congenital adrenal hyperplasia $(\mathrm{CAH})$ are caused by 21 -hydroxylase deficiency, measurement of the plasma 17-hydroxyprogesterone (17-OHP) concentration that accumulates as a result of the block in steroidogenesis is widely used for early and rapid diagnosis. ${ }^{1-3}$ It has been recommended that blood samples should not be collected until 24 hours after birth to eliminate the placental influence on plasma 17-OHP values. ${ }^{4}$ In recent years, this institute has received an increasing number of requests for the measurement of 17-OHP concentrations in plasma samples collected from preterm infants. Indications for this test include unexplained hyponatraemia, persistent vomiting, prominent labia minora in female preterm infants, and a positive family history of CAH. Occasionally, plasma 17-OHP concentrations have been sufficiently raised to suggest a diagnosis of 21-hydroxylase deficiency, but none of the infants have suffered adrenal disorders.

We undertook a systematic study of plasma 17OHP concentrations in a group of preterm and term infants who were ill from a variety of causes. None had CAH and the results provide new reference data for the interpretation of plasma 17-OHP measurements in neonates.

\section{Patients and methods}

Forty seven patients and 53 healthy term control infants were studied. They were divided into 4 groups; well term infants (control), ill term infants, well preterm infants, and ill preterm infants. Gestational age was assessed by the method of Ballard et $\mathrm{al} .{ }^{5}$ Clinical details are summarised in the
Table. Infants were ill from a variety of causes including severe hyaline membrane disease requiring assisted ventilation, intraventricular haemorrhage, hydrops fetalis, septicaemia, congenital pneumonia, perinatal asphyxia, major abdominal surgical conditions, and severe congenital heart disease. They were studied between age 2 and 10 days when heelprick blood samples were collected for routine investigations. A total of 51 plasma 17-OHP measurements were available for analysis and were compared with the results of 17-OHP measurements in plasma samples collected from the 53 healthy term control infants.

Plasma 17-OHP concentrations were determined by radioimmunoassay using a ${ }^{125}$ I-radioligand and an antiserum coupled to a magnetisable solid phase support. The sensitivity of the assay was 4.7 $\mathrm{pg} /$ tube, equivalent to $0.7 \mathrm{nmol} / 1$. Intra-assay coefficient of variation did not exceed $5.5 \%$ for low, medium, and high pools. The inter-assay coefficients of variation for low, medium, and high pools were $6.4 \%, 5.1 \%$, and $4.1 \%$ respectively. The cross reactivity of the antiserum was $8 \%$ for progesterone,

Table Clinical details of infants studied

\begin{tabular}{|c|c|c|c|}
\hline Clinical details & Term ill & Preterm well & Preterm ill \\
\hline $\begin{array}{l}\text { No of infants } \\
\text { Gestational age (weeks) }\end{array}$ & 12 & 9 & 26 \\
\hline $\begin{array}{l}\text { mean } \pm S D \\
\text { range }\end{array}$ & $\begin{array}{l}38 \cdot 7 \pm 1 \cdot 4 \\
37-40\end{array}$ & $\begin{array}{l}33 \cdot 7 \pm 2 \cdot 6 \\
28-36\end{array}$ & $\begin{array}{l}32 \cdot 0 \pm 3 \cdot 0 \\
27-37\end{array}$ \\
\hline \multicolumn{4}{|l|}{ Birthweight (g) } \\
\hline 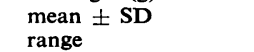 & $\begin{array}{l}3090 \pm 500 \\
2160-3930\end{array}$ & $\begin{array}{l}1961 \pm 572 \\
920-3000\end{array}$ & $\begin{array}{l}1678 \pm 502 \\
850-2500\end{array}$ \\
\hline Age at study (days) & & & \\
\hline$\underset{\text { range }}{\text { mean }} \pm \mathrm{SD}$ & $\begin{array}{l}4 \cdot 2 \pm 3 \cdot 8 \\
2-16\end{array}$ & $\begin{array}{l}3 \cdot 4 \pm 1 \cdot 9 \\
2-8\end{array}$ & $\begin{array}{l}3 \cdot 9 \pm 2 \cdot 8 \\
2-18\end{array}$ \\
\hline
\end{tabular}


$3.8 \%$ for 21 -deoxycortisol, $0.6 \%$ for 11 -deoxycortisol, and $<0.04 \%$ for cortisol. Radioimmunoassay data processing was performed and quality controlled using published methods. ${ }^{6} 7$

Since the distribution of the data was markedly skewed, logarithmic transformation gave agreement between the geometric means and medians. Statistical comparison between the groups on transformed data was performed using Student's unpaired $t$ test.

\section{Results}

The mean and range for plasma 17-OHP concentrations in term (well and ill) and preterm (well and ill) infants are shown in the Figure. In healthy term infants mean plasma 17-OHP was (mean \pm SD) $4.4 \pm 2.6 \mathrm{nmol} / 1$. Ill term infants, however, had a significantly higher mean plasma 17-OHP concentration of (mean $\pm \mathrm{SD}$ ) $10.6 \pm 7.5 \mathrm{nmol} / \mathrm{l}$ $(P<0.001)$. In well preterm infants the plasma 17-OHP concentration was (mean \pm SD) $13.6 \pm$ $11.4 \mathrm{nmol} / \mathrm{l}$, which was significantly higher than the value in healthy term infants $(P<0.05)$. The

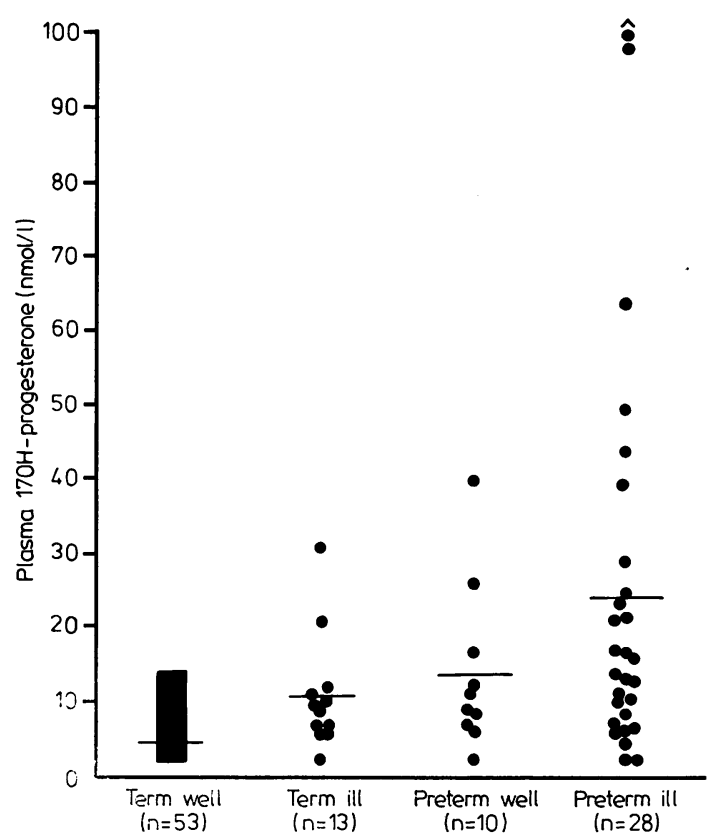

Figure Mean and range for plasma 17. hydroxyprogesterone concentrations in term and preterm infants who were either healthy or ill. The causes of illness are described in the methods. Some infants had repeat blood samples collected and ' $n$ ' refers to the number of $17 \mathrm{OHP}$ measurements in each group; o represents a value of $110 \mathrm{nmol} / \mathrm{l}(34 \cdot 1 \mathrm{ng} / \mathrm{ml})$. Conversion: SI to traditional units-17-

hydroxyprogesterone: $1 \mathrm{nmol} / \mathrm{l} \approx 0.31 \mathrm{ng} / \mathrm{ml}$. highest plasma 17-OHP concentrations occurred in ill preterm infants (mean \pm SD) $24.39 \pm 27 \cdot 50$ $\mathrm{nmol} / \mathrm{l}$, reaching as high as $110 \mathrm{nmol} / \mathrm{l}$, (34.1 $\mathrm{ng} / \mathrm{ml})$. Although these values were appreciably higher than those of ill term infants $(P<0.01)$, they were not significantly different from those of well preterm infants.

\section{Discussion}

This study shows that the normal reference range for plasma 17-OHP concentrations in healthy term infants is unsuitable for the interpretation of values in neonates who are either ill or preterm, or both. Non-adrenal disorders such as severe congenital heart disease or abdominal surgical conditions can increase plasma 17-OHP concentrations to more than $30 \mathrm{nmol} / 1(9 \cdot 3 \mathrm{ng} / \mathrm{ml})$. Although plasma 17-OHP concentrations in untreated infants with 21-hydroxylase deficiency far exceed these values, ${ }^{4}$ Pang et al, ${ }^{8}$ reported a 10 day old term infant ill with sepsis and hyponatraemia who had a plasma 17-OHP concentration of $64.5 \mathrm{nmol} / 1(20 \mathrm{ng} / \mathrm{ml})$. Steroid replacement treatment for salt losing CAH was started, but when the diagnosis was reassessed at age 3 months, after steroid treatment had been stopped, the results for plasma steroid measurements were normal. A marked increase in the plasma 17-OHP concentration has been reported in infants with acute salt wasting caused by pseudohypoaldosteronism. ${ }^{9}{ }^{10}$ Cortisol production in this disorder is normal and chronic glucocorticoid replacement treatment is entirely inappropriate.

Plasma 17-OHP concentrations were high in both well and ill preterm infants, and values as high as $40 \mathrm{nmol} / 1(12.4 \mathrm{ng} / \mathrm{ml})$ were found in the former group. A similar increased plasma 17-OHP concentration has been reported in the few studies of neonates to include preterm infants. ${ }^{11} 12$ This study showed markedly high plasma $17-\mathrm{OHP}$ concentrations in preterm infants who were very ill from a variety of non-adrenal disorders. In some, plasma concentrations as high as those seen in infants with untreated CAH were observed. ${ }^{4}$ As expected, ill preterm infants were generally lighter and more immature than their healthy counterparts. Birthweight and gestational age were not, however, appreciably different between term and preterm infants.

The number of requests for measurement of plasma 17-OHP concentrations in preterm infants with persistent hyponatraemia are increasing. In most instances hyponatraemia is the result of a defect in sodium transport associated with immaturity, ${ }^{13}$ but it occasionally is caused by inappropriate fluid replacement. It is essential that different reference data be used for the interpretation 
of plasma 17-OHP concentrations in both well and ill preterm infants, and in ill term infants.

In recent years sensitive assays for the measurement of 17-OHP concentrations in capillary blood collected onto filter paper have been developed.12 14 The technique has been applied in several countries to screen infants for CAH at birth. ${ }^{15-17}$ It is noteworthy, however, that false positive 17-OHP values have been found exclusively in preterm infants. The interpretation of plasma 17-OHP values in newborn infants must take account of factors such as gestational and postnatal age, birthweight, and the presence of any serious non-adrenal disorder such as sepsis or severe perinatal asphyxia. If necessary, a repeat measurement of plasma 17-OHP concentration after treatment for the primary illness, or possibly an assessment of the plasma 17-OHP response to short acting adrenocorticotropic hormone (Synacthen) stimulation usually provides sufficient information to interpret an initial raised plasma 17-OHP value.

The cause of increased plasma 17-OHP concentrations in ill newborn infants is unclear. The cross reactivity of the 17-OHP antiserum used in the radioimmunoassay was $8 \%$ for progesterone. Although cord blood 17-OHP and progesterone concentrations are raised, their concentration in infant plasma decreases rapidly after birth. ${ }^{418} \mathrm{~A}$ response to stress is not the entire explanation since several ill infants with raised plasma 17-OHP concentrations had low plasma cortisol concentrations. Plasma concentrations of cortisol in term infants fall appreciably at 1 week of age and then rise progressively towards adult values during the first year of life. ${ }^{18}$ Parallel changes in corticosteroid binding globulin concentrations occur during this time and reflect maturation of hepatic synthesis. ${ }^{19}$ This may be delayed in the preterm infant. Since only cortisol and cortisone are to a great extent bound to corticosteroid binding globulin, this may explain the divergence in early postnatal plasma concentrations of 17-OHP and cortisol in some stressed preterm infants.

We thank Professor Gray for permission to study infants under his care; the staff in the Tenovus Supra-Regional Steroid Assay Laboratory; Dr R G Newcombe for advice.

\section{References}

1 Barnes ND, Atherden SM. Diagnosis of congenital adrenal hyperplasia by measurement of plasma 17hydroxyprogesterone. Arch Dis Child 1972; 47: 62-5.

2 Youssefnejadian E, David R. Early diagnosis of congenital adrenal hyperplasia by measurement of 17 hydroxyprogesterone. Clin Endocrinol (Oxf) 1975; 4: 451-4.

3 Hughes IA, Winter JSD. The application of serum $17 \mathrm{OH}$-progesterone radioimmunoassay to the diagnosis and management of congenital adrenal hyperplasia. J Pediatr 1976; 88: 776-3.
4 Hughes IA, Riad-Fahmy D, Griffiths K. Plasma 17OHprogesterone concentrations in newborn infants. Arch Dis Child 1979; 54: 347-9.

5 Ballard J, Kazmaier K, Driver M. A simplified assessment of gestational age (abstract). Pediatr Res 1977; 11 : 374.

- Rodbard D, Hutt DM. Statistical analysis of radioimmunoassay and immunoradiometric (labelled antibody) assays: a generalised weighted iterative least squares method for logistic curve fitting. In: Proceedings of a Symposium on Radioimmunoassay and Related Procedures in Medicine, Istanbul 1973. Vienna: International Atomic Energy Agency, 1974: 165.

7 Kemp KW, Nix ABJ, Wilson DW, Griffiths K. Internal quality control of radioimmunoassays. $J$ Endocrinol 1978; 76: 203-10.

8 Pang S, Levine LS, Chow DM, Faiman C, New MI. Serum androgen concentrations in neonates and young infants with congenital adrenal hyperplasia due to 21-hydroxylase deficiency. Clin Endocrinol (Oxf) 1979; 11: $575-84$.

9 Savage MO, Atherden S, Grant DB. Raised plasma $170 \mathrm{H}$-progesterone in hyponatraemic infants without congenital adrenal hyperplasia (abstract). Arch Dis Child $1981 ; 56: 812$.

10 Bommen M, Brook CGD. Pseudohypoaldosteronism. Response to long-term treatment with indomethacin. Arch Dis Child 1982; 57: 718-20.

11 Forest M-G, Cathiard A-M. Ontogenic study of plasma $17 \alpha$-hydroxyprogesterone in the human. I. Postnatal period. Evidence for a transient ovarian activity in infancy. Pediatr Res 1978; 12: 6-11.

12 Sólyom J, Hammond GL, Vihko R. A method for identification and follow-up of patients with a steroid-21hydroxylase deficiency. Clin Chim Acta 1979; 92: 117-24.

13 Guignard JP. Renal function in the newborn infant. Pediatr Clin North Am 1982; 29: 777-90.

14 Pang S, Hotchkiss J, Drash AL, Levine LS, New MI. Microfilter paper method for 17 alpha-hydroxyprogesterone radioimmunoassay: its application for rapid screening for congenital adrenal hyperplasia. J Clin Endocrinol Metab 1977; 45: 1003-8.

15 Pang S, Murphy W, Levine LS, et al. A pilot newborn screening for congenital adrenal hyperplasia in Alaska. J Clin Endocrinol Metab 1982; 55: 413-20.

16 Cacciari E, Balsamo A, Cassio A, et al. Neonatal screening for congenital adrenal hyperplasia using a microfilter paper method for 17- $\alpha$-hydroxyprogesterone RIA. In: Chiumello G, Sperling M. eds. Recent progress in pediatric endocrinology. Serono Series. New York: Raven, 1982: in press.

17 Shimozawa K, Saito N, Sakurada N, et al. A pilot neonatal mass-screening study for congenital adrenal hyperplasia due to 21-hydroxylase deficiency in Japan (abstract). In: Proceedings of the International Meeting on Neonatal Screening, Tokyo 1982. 109.

18 Sippell WG, Dörr HG, Bidlingmaier F, Knorr D. Plasma levels of aldosterone, corticosterone, 11-deoxycorticosterone, progesterone, 17-hydroxyprogesterone, cortisol, and cortisone during infancy and childhood. Pediatr Res 1980; 14: 39-46.

19 Hadjian AJ, Chedin M, Cochet C, Chambaz EM. Cortisol binding to proteins in plasma in the human neonate and infant. Pediatr Res 1975; 9: 40-5.

Correspondence to Dr I A Hughes, Department of Child Health, Welsh National School of Medicine, Heath Park, Cardiff CF4 4XN.

Received 17 March 1983 